http://https://ejournal.iai-tribakti.ac.id/index.php/perbankan

\title{
Implementasi Metode TOPSIS Dalam Pemilihan Jasa Pangkas Rambut Dimasa Pandemi Covid 19
}

\section{Implementation of The TOPSIS Method In Selecting Haircut Services During The Covid 19 Pandemic}

\author{
Ririn Wahyu Arida \\ Universitas Islam Kadiri \\ ririn78wahyuarida@gmail.com
}

\begin{abstract}
The Covid pandemic requires that all activities be carried out by implementing health protocols. Likewise, hairdressing services must also apply health protocols. The purpose of this study was to determine what haircut services were used by respondents during the Covid 19 pandemic using the TOPSIS method. The criteria for this research are price, service, style, health protocol and location. From the results of the Preference Value, it can be seen that the modern haircut (Barbershop) has a greater Vi Preference Value of 8.151123764, when compared to the preference value of conventional haircuts of 0.428269966 . This shows that respondents prefer to use modern haircut services (barbershop) during the Covid 19 pandemic. On the grounds that respondents feel comfortable with the services provided by modern haircut services (barbershop), besides that modern haircut services (barbershop) have advantages. up-to-date hair styles and still run health protocols even though the price is more expensive compared to conventional haircuts.
\end{abstract}

Keywords: TOPSIS, Covid 19 Pandemic, Purchase Decisions, Quantitative Management

\begin{abstract}
Abstrak
Pandemi Covid mengharuskan semua kegiatan dilakukan dengan menerapkan protokol kesehatan. Demikaian pula jasa pangkas rambut yang juga harus menerapkan protokol kesehatan. Tujuan dari penelitian ini adalah untuk mengetahui jasa pangkas rambut apa yang digunakan oleh responden selama masa Pandemi Covid 19 dengan menggunakan metode TOPSIS. Adapun yang menjadi kriteria dalam peneliian ini adalah harga, pelayanan, style, protokol kesehatan dan lokasi. Dari hasil Nilai Preferensi dapat diketahui
\end{abstract}


bahwa Pangkas rambut modern (Barbershop) mempunyai Nilai Preferensi Vi yang lebih besar yaitu sebesar 8,151123764, apabila dibandingkan dengan nilai preferensi pangkas rambut konvensional sebesar 0,428269966. Hal ini menunjukkan bahwa responden lebih memilih menggunakan jasa Pangkas rambut modern (Barbershop) di masa Pandemi Covid 19. Dengan alasan bahwa responden merasa nyaman dengan pelayanan yang diberikan oleh jasa pangkasrambut modern ( barbershop), selain itu jasa pangkas rambut modern (barbershop) memiliki kelebihan style rambut yang kekinian dan tetap menjalankan protokol kesehatan walaupun harga lebih mahal di bandingkan dengan pangkas rambut konvensional.

Kata Kunci: TOPSIS, Pandemi covid 19, Keputusan Pembelian, Manajemen Kuantitatif

\section{Pendahuluan}

Pandemi covid 19 yang melanda dunia membawa dampak pada semua aspek kehidupan. Dampak paling banyak dirasakan di bidang kesehatan dan ekonomi. Dampak Covid 19 di bidang ekonomi mendorong para pelaku ekonomi untuk selalu berinovasi dan merubah metode agar sesuai dengan kondisi yang terjadi saat ini. Salah satu pelaku ekonomi yang ikut terdampak dimasa pandemi covid 19 adalah jasa pangkas rambut. Seperti kita ketahui bersama sejak Pandemi Covid 19 melanda Indonesia pada bulan maret 2020 mengharuskan semua kegiatan di lakukan di rumah, belajar, bekerja dan beribadah di rumah. Akan tetapi ada satu hal yang tidak bisa dilakukan di rumah yaitu pangkas rambut. Walaupun sekarang banyak di jual alat pangkas rambut otomatis yang memudahkan pengguna dalam memangkas rambut akan tetapi tidak semua orang mempunyai kemampuan atau skill di bidang pangkas rambut. Kelemahan dari alat pangkas rambut otomatis bisa digunakan kalau pengguna mengabaikan style / gaya/ rambut yang akan dipangkas. 


\section{Ririn Wahyu Arida | Implementasi Metode Topsis...}

Hal ini mendorong konsumen untuk tetap datang ke tempat jasa pangkas rambut baik yang konvensional maupun modern ( Barber Shop ). Kedatangan konsumen pangkas rambut ke lokasi tentu merupakan dilema tersendiri di masa Pandemi Covid 19 karena kebijakan PSBB, Protokol Kesehatan, yang harus di patuhi baik oleh Konsumen Maupun Jasa Pangkas Rambut itu sendiri.

\section{Sistem Pendukung Keputusan}

Sistem Pendukung Keputusan sangat membantu pihak manajemen dalam pengambilan keputusan dengan menggunakan data dan model. Sistem ini merupakan bagian dari sistem informasi yang berbasis komputer(termasuk sistem berbasis pengetahuan atau manajemen pengetahuan). Hal yang perlu diperhatiakan dalam penggunaan Sistem Pendukung Keputusan adalah sistem ini tidak menggantikan tugas- tugas dari seorang manajer, melainkan hanya sebagai alat penunjang atau tool bagi mereka. Bahkan sistem Pendukung Keputusan ini juga bisa di gunakan oleh pihak pihak di luar perusahaan yang memerlukan pemecahan masalah semi struktural. Berikut adalah beberapa difinisi Sistem Pendukung Keputusan menurut para ahli :

a. Sistem Pendukung Keputusan adalah sistem berbasis model yang terdiri dari prosedur prosedur dalam pemrosesan data dan pertimbangan untuk membantu manajer dalam mengambil keputusan. ${ }^{1}$

b. sistem yang digunakan untuk mendukung dan membantu pihak manajemen melakukan pengambilan keputusan pada kondisi semi terstruktur dan tidak terstruktur. ${ }^{2}$

1 HermawanAsep. Penelitian Bisnis Paradigma Kuantitatif. Jakarta: Gramedia Widiyasarana Indonesia, 2005.

${ }^{2}$ Turban, Efraim, Jay E Aronson dan Ting Peng Liang. Decision Support Systems and Intelligent Systems. New Jersey: PrenticeHal, 2005. 
c. sistem penghasil informasi spesifik yang ditujukan untuk memecahkan suatu masalah tertentu yang harus dipecahkan oleh manajer pada berbagai tingkatan. ${ }^{3}$

d. suatu sistem informasi berbasis komputer yang menghasilkan berbagai alternatif keputusan untuk membantu manajemen dalam menangani berbagai permasalahan yang terstruktur atupun tidak terstruktur dengan menggunakan data dan model. ${ }^{4}$

e. Sistem Pendukung Keputusan merupakan sistem informasi yang menyediakan informasi, pemodelan dan pemanipulasian data yang mampu untuk mendukung anlisi data secara $e d$ hoc dan pemodelan keputusan serta berorientasi pada perencanaan masa depan. ${ }^{5}$

\section{Manfaat Sistem Pendukung Keputusan}

Sistem Pendukung Keputusan dapat memberikan manfaat bagi pihak pihak yang menggunakannya. Menurut kadarsah ${ }^{6}$ ada beberapa manfaat yang dapat diambil dari Sistem Pendukung Keputusan yaitu

a. Dengan menggunakan Sistem Pendukung Keputusan dapat memperluas kemampuan dalam pengambilan keputusan dalam memproses data atau informasi bagi pemakainya

b. Dengan menggunakan Sistem Pendukung Keputusan dapat membantu memecahkan masalah yang komplek dan tidak terstruktur

c. Dengan menggunakan Sistem Pendukung Keputusan solusi pemecahan masalah menjadi lebih cepat dan hasilnya bisa diandalkan

\footnotetext{
${ }^{3}$ Raymond McLeod, Jr. Sistem Informasi Edisi 7 Jilid 2. Jakarta: Prenhallindo, 2001.

${ }^{4}$ Littlejhon, steven w\&keren A.fos.2009.teori komunikasi, edisi 9.jakarta : humanika salemba. teori komunikasi, edisi 9. jakarta: humanika salemba, 2009.

${ }^{5}$ Kusrini. Konsep Dan Aplikasi Sistem Pendukung Keputusan. Yogyakarta: ANDI, 2007.

6 Kadarsah, Suryadi. Sistem Pendukung KeputusanSuatu Wacana Struktural Idealisasi Dan Implementasi Konsep Pengambilan Keputusan. Bandung: Remaja Rosdakarya, 2002.
} 
Ririn Wahyu Arida | Implementasi Metode Topsis...

d. Penggunaan Sistem Pendukung Keputusan mampu menstimulasi pengambil keputusan dalam memahami persoalannya, karena mampu menyajikan berbagai alternatif pemecahan.

\section{TOPSIS}

Technique For Order Preference By Similarity To Ideal Solution atau biasa di sebut dengan TOPSIS adalah salah satu alat pada Sistem Pendukung Keputusan yang berdasarkan pada konsep dimana alternatif terplih terbaik tidak hanya memiliki jarak terdekat dari solusi ideal positif, tapi juga memiliki jarak terjauh dari solusi ideal negatif. Metode ini banyak digunakan karena memiliki konsep yang sederhana dan mudah di pahami serta memiliki kemampuan untuk mengukur kinerja relatif dari alternatif - alternatif keputusan dalam bentuk matematis yang sederhana.

Metode TOPSIS ini pertama kali di perkenalkan oleh Yun dan Hwang pada tahun 1981. Pada waktu itu Metode TOPSIS digunakan untuk memecahkan masalah multikriteria. TOPSIS mampu memberikan solusi ideal positif yang relatif dan buakan solusi ideal positif yang absolut. Pada Metode TOPSIS klasik nilai bobot suatu kriteria telah diketahui dengan jelas, dimana setiap bobot kriteria ditentukan berdasarkan tingkat kepentingannya menurut pengambil keputusan. Berikut adalah skala tingkat kepentingan yang digunakan dalam metode TOPSIS.

Tabel 1

Skala Tingkat Kepentingan TOPSIS

\begin{tabular}{cl}
\hline Nilai skala tingkat kepentingan & \multicolumn{1}{c}{ Keterangan } \\
\hline 1 & Sangat buruk \\
2 & Buruk \\
3 & Cukup \\
4 & Baik \\
5 & Sangat baik \\
\hline
\end{tabular}


Kemudian Yoon dan Hwang mengembangkan metode TOPSIS berdasarkan intuisi dimana alternatif yang mempunyai jarak terkecil dari solusi ideal positif dan jarak terbesar dari solusi ideal negatif dari sudut pandang geometris dengan menggunakan jarak Euclidean merupakan alternatif yang paling ideal.

Metode TOPSIS mempertimbangkan jarak terhadap solusi ideal positif dan jarak terhadap solusi ideal negatif secara bersamaan. Solusi optimal yang di dapat dalam metode TOPSIS, dengan menentukan kedekatan relatif suatu alternatif terhadap solusi ideal positif. Kemudian TOPSIS akan merangking alternatif berdasarkan prioritas nilai kedekatan relatif suatu alternatif terhadap solusi ideal positif. Alternatif yang telah dirangking kemudian dijadikan sebagai referensi bagi pengambil keputusan untuk memilih solusi terbaik yang diinginkan. Metode TOPSIS banyak digunakan untuk menyelesaikan pengambilan keputusan secara praktis. Hal ini disebabkan konsepnya sederhana dan mudah dipahami. Penggunaan Suatu metode pasti memiliki kelebihan dan kekurangan. Berikut adalah kelebihan dan kekurangan penggunan metode TOPSIS.

Kelebihan peggunaan metode TOPSIS adalah:

1. Konsepnya sederhana dan mudah dipahami, kesedarhanaan ini dilihat dari alur proses metode TOPSIS yang tidak begitu rumit. Karena menggunakan indikator kriteria dan variabel alternatif sebaga pembantu untuk menentukan keputusan

2. Memiliki kemampuan untuk mengukur kinerja relatif dari alternatif-alternatif keputusan dalam bentuk matematis yang sederhana.

3. Dapat digunakan sebabai metode pengambilan keputusan yang lebih cepat 
Ririn Wahyu Arida | Implementasi Metode Topsis...

\section{Kekurangan Metode TOPSIS}

1. Untuk menghasilkan output yang lebih maksimal harusdikombinasikan dengan metode lain semisal AHP dikarenakan belum adanya penentuan bobot prioritas yang menjadi prioritas hitungan terhadap kriteria, yang berguna untuk meningkatkan validitas nilai bobot perhitungan kriteria.

2. Belum adanya bentuk linguistik untuk penilaian alternatif terhadap kriteria, biasanya bentuk linguistik ini di interpretasikan dalam sebuah bilangan fuzzy.

3. Metode TOPSIS belum memiliki mediator seperti hirarki jika di proses secara mandiri maka dalam ketepatan pengambilan keputusan cenderung belum bisa menghasilkan sebuah keputusan yang sempurna.

\section{Pangkas Rambut}

Tidak diketahui secara pasti kapan pangkas rambut mulai ada di Indonesia. Sejarah pangkas rambut bahkan disebut sudah ada sejak jaman purba, sebelum Robert Hincliffe menemukan gunting. Jejak Pangkas rambut di Indonesia bisa dilihat dari foto- foto kuno yang ada di KITLV Belanda. Lembaga ini menyimpan koleksi foto para tukang cukur jalanan di beberapa kota besar di Indonesia mulai periode 1911 sampai 1930. Sedangkan Barbershop mulai muncul bersaman dengan munculnya revolusi industri pada abad ke 18. Pada masa itu para pekerja pabrik di wajibkan berambut pendek. Para orang kaya Eropa pun mencitrakan diri sebagai sosok yang terhormat melalui potongan rambut pendek.

Di Indonesia Barbershop sudah ditemukan sejak jaman penjajahan belanda. Bahkan ada satu barbershop yang melegenda yang berada di area petak sembilan yang berada di jalan Pintu Besar Selatan Jakarta Barat yang di kenal dengan nama ko tang. Barbershop ini di dirikan oleh Po Kin Tien pada tahun 1936 hingga sekarang. 
Ada penanda yang seragam pada sebuah barbershop yang berupa sebuah lampu yang terdiri dari 3 warna merah, putih, dan biru. Ketiga warna dalam lampu tersebut memiliki makna filosofi tersendiri. Warna merah berarti darah, warna biru berarti pembuluh darah dan warna putih mempunyai arti perban yang steril. Ketiga warna ini berbentuk spiralyang menunjukkan perban yang dicuci dan diperas.

Dari filosofi lampu barbershop diatas maka bisa kita ketahu pada jaman dahulu pemangkas rambut tidak hanya melayani pangkas rambut saja tetapi juga menjadi seorang ahli bedah. ${ }^{7}$

Metode TOPSIS pernah di terapkan pada penelitian windarto ${ }^{8}$ dengan judul Implementasi Metode TOPSIS Dalam Memberikan Reward Kepada Pelanggan. Dalam penelitian di peroleh hasil bahwa metode TOPSIS lebih lebih baik dari pada metode SAW. Hal serupa juga dikemukan oleh Muzakir ${ }^{9}$. Pada Penelitian lain berjudul Kombinasi Metode AHP Dan TOPSIS Pada Sistem Pendukung Keputusan Murti ${ }^{10}$ di peroleh hasil bahwa metode AHP dan TOPSIS merupakan kombinasi yang bisa diterapkan dalam sistem pendukung keputusan dengan memperhatikan kriteria - kriteria yang dilakukan pembobotan harus menggunakan ahli yang paham betul dengan objek yang akan di teliti. Hal ini sejalan dengan penelitian Juliyanti dan

7 https://www.liputan6.com/lifestyle/read/4046240/cerita-akhir-pekan-sejarah-danperkembangan-tukang-cukur-di-indonesia

8 Windarto, Agus Perdana. "Implementasi Metode Topsis Dan Saw Dalam Memberikan Reward Pada Pelanggan.” Kumpulan Jurnal Ilmu Komputer (KLIK) Vol 4 No 1 Februari ISSN 2406 - 7857, 2017: 14

${ }^{9}$ Muzakir, Irvan. "Penerapan Metode Topsis Untuk Sistem Pendukung Keputusan Penentuan Keluarga Miskin Pada Desa Panca Karsa II." ILKOM Jurnal Ilmiah Vol 9 Nomor 3 Desember, 2017: 8.

${ }^{10}$ Murti, Ahmad Abdul Chamid \& Abdul. "Kombinasi Metode Ahp Dan Topsis Pada Istem Pendukung Keputusan.” Prosiding SNATIF ke 4 ISBN 978-602-1180-50-1, 2017: 5. 
Ririn Wahyu Arida | Implementasi Metode Topsis...

Mukhlas ${ }^{11}$. Sedangkan menurut Wawan Firgiawan ${ }^{12}$ Metode AHP lebih baik dari pada metode SAW dan TOPSIS

\section{Metode}

Pada penelitian ini pengumpulan data di lakukan dengan menyebar kuesioner, dimana pemilihan responden dilakukan secara sengaja kepada mahasiswa Universitas Islam Kadiri Fakultas Ekonomi Semester 3 untuk menentukan Alternatif dan Krtiteria

Langkah - Langkah Penyelesaian Metode TOPSIS

1. Normalisasi nilai atribut yang disesuaikan dengan jenis a tribut untuk membentuk matriks ternormalisasi (R) dapat menggunakan persamaan berikut

$$
\mathrm{r}_{\mathrm{ij}}=\frac{x_{i j}}{\sqrt{\sum_{i=1}^{m} x_{i j}{ }^{2}}}
$$

Dimana : $(\mathrm{i}=1,2, \ldots, \mathbf{n} ; \mathbf{j}=1,2, \ldots, \mathrm{m})$

2. Membuat matriks keputusan yang ternormalisasi terbobot (Y).Perkalian antara bobot dengan nilai setiap atribut dihitung menggunakan persamaan berikut

$$
\mathrm{y}_{\mathrm{ij}}=\mathrm{w}_{\mathrm{i}} \mathrm{r}_{\mathrm{ij}}
$$

11 Juliyanti, dan Mohamad Isa Irawan dan Mukhlas. "Pemilihan Guru Berprestasi Menggunakan Metoe Ahp Dan Topsis." Prosiding Seminar Nasional Penelitian Pendidikan dn Penerapan MIPA Fakultas MIPA Universitas Negri Yogyakarta , 2011: 6.

${ }^{12}$ Wawan firgiawan, Nuralamsah Zulkarnain, Sugiarto Cokro Wibowo. "Komparasi Algoritma Saw, Ahp Dan Topsis Dalam Penentuan Uang Kuliah Tunggal (UKT).” JCIS (Journal Of Computer and Information System) Vol 1 issue 2 ISSN 2622-0881, 2019: 11. 
3. Menentukan matriks solusi ideal positif $\left(\mathrm{A}^{+}\right)$dan matriks solusi ideal negatif $\left(\mathrm{A}^{-}\right)$dapat menggunakan persamaan

$$
\begin{aligned}
& \mathrm{A}^{+}=\mathrm{y}_{1}^{+}, \mathrm{y}_{2}^{+}, \ldots, \mathrm{y}_{\mathrm{j}}^{+} \\
& \mathrm{A}^{-}=\mathrm{y}_{1}^{-}, \mathrm{y}_{2}^{-}, \ldots, \mathrm{y}_{\mathrm{j}}^{-} \\
& \text {dengan } \\
& \mathrm{y}_{\mathrm{j}}^{+}=\mathrm{max}_{\mathrm{i}} \mathrm{y}_{\mathrm{ij}} ; \quad \text { jika } \mathrm{j} \text { adalah atribut keuntungan } \\
& \min _{\mathrm{i}} \mathrm{y}_{\mathrm{ij}} ; \min _{\mathrm{i}} \mathrm{y}_{\mathrm{ij}} ; \quad \text { jika } \mathrm{j} \text { adalah atribut keuntungan } \\
& \mathrm{y}_{\mathrm{j}}^{-}=\max _{\mathrm{i}} \mathrm{y}_{\mathrm{ij}} ; \quad \text { jika } \mathrm{j} \text { adalah atribut biaya }
\end{aligned}
$$

4. Menentukan jarak antara nilai setiap alternatif dengan matriks solusi ideal positif dan matriks solusi ideal negatif.

a. Jarak antara alternatif dengan solusi ideal positif dapat menggunakan persamaan berikut

$$
D_{i}^{+}=\sqrt{m_{j=i}^{m}\left(y_{j}^{+}-y_{i j}\right)^{2}}
$$

b. Jarak antara alternatif dengan solusi ideal negatif dapat menggunakan persamaan berikut

$$
D_{i}^{-}=\sqrt{j_{j=i}^{m}\left(y_{i j}-y_{j}^{-2}\right)^{2}}
$$

5. Menentukan nilai preferensi untuk setiap alternatif. Nilai preferensi merupakan kedekatan suatu alternatif terhadap solusi ideal. Nilai 
Ririn Wahyu Arida | Implementasi Metode Topsis...

preferensi untuk setiap alternatif (Vi) dapat menggunakan persamaan berikut

$$
V_{i}=\frac{D_{i}^{-}}{D_{i}^{-} D_{i}^{+}}
$$

\section{Hasil dan Pembahasan}

\section{Langkah - Langkah Penyelesaian Metode TOPSIS}

Sebelum Menggunakan Metode TOPSIS harus di tentukan dulu Alternatif dan kriteria beserta bobotnya (Tabel 1). Kriteria ini dijadikan dasar atau acuan pagi peneliti untuk menentukan pangkas rambut terbaik dimaa pandemi. Adapun Kriteria yang di gunakan dalam penelitian ini adalah Kualitas layanan, Harga, Protokol kesehatan, Style, Lokasi. Sedangkan Alternatif yang di gunakan adalah Pangkas rambut konvensional dan Modern (barbershop).

Tabel 2

Bobot Kriteria

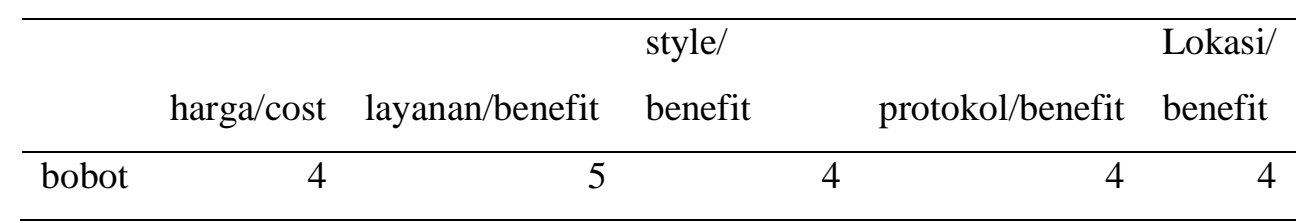

Dari tabel diatas bisa kita lihat bahwa layanan mempunyai bobot paling tinggi dibandingkan dengan kriteria yang lainnya. Nilai bobot layanan sebesar 5 yang artinya sangat baik. Hal ini dikarenakan konsumen pangkas rambut lebih mementingkan layanan di bandingkan harga, protokol kesehatan dan lokasi. Sedangkan untuk harga, protokol kesehatan dan lokasi mempunyai bobot dengan nilai 4 yang artinya baik. Untuk penentuan bobot 
kriteria ini bisa dilihat pada tabel tingkat skala kepentingan TOPSIS (Tabel $1)$.

Tabel 3

Alternatif \& Kriteria

\begin{tabular}{lccccc}
\hline & & & style/ & Lokasi/ \\
& harga/cost & layanan/benefit & benefit & protokol/benefit & benefit \\
\hline Konvensional & 10000 & 3 & 2 & 2 & 3 \\
Barbeshop & 35000 & 4 & 5 & 4 & 4 \\
\hline
\end{tabular}

Pada tabel 3 diatas di isi juga bobot untuk masing masing kriteria dengan memperhitungkan apakah kriteria tersebut mempunyai kelompok biaya/cost ataukah kelompok manfaat/benefit. Penggolongan ini penting karena nanti akan digunakan dalam menentukan nilai pada matrik ideal positif dan matrik ideal negatif. Adapun cara memberikan bobot pada kelompok biaya/cost dan kelompok manfaat/benefit berbeda. Untuk kriteria yang kelompok biaya/cost semakin tinggi angka pada bobotnya artinya semakin rendah nilainya (berbanding terbalik). Sebagai contoh kriterian harga semakin murah harganya maka semakin baik nilainya. Sebaliknya untuk kriteria dengan kelompok manfaat atau benefit semakin tinggi angka pada bobotnya artinya semakin tinggi pula nilainya (berbanding lurus). Untuk pengisian angka bisa di sesuaikan dengan tabel tingkat skala kepentingan TOPSIS (Tabel 1).Apabila penentuan alternatif dan kriteria beserta pembobotan sudah selesai di lakukan maka langkah langkah metode TOPSIS bisa dilanjutkan.

1. Normalisasi nilai atribut y ang dise suaikan de ngan je nis atribut untuk membentuk matriks ternormalisasi(R) dapat menggunakan persamaan berikut 
Ririn Wahyu Arida | Implementasi Metode Topsis...

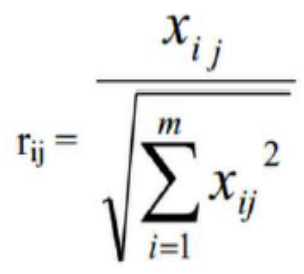

Dimana : $(i=1,2, \ldots, n ; j=1,2, \ldots, m)$

Untuk mempermudah pengisian dalam matrik Ternormalisasi, tentukan dulu pembagi yang ada pada persamaan di atas. Dengan cara mencari akar dari nilai kriteria ( tabel 3) yang dikuadratkan. Hal ini di lakukan untuk semua kriteria yang ada di tabel 3. Setelah didapatkan nilai pembagi kemudian mencari hasil pembagian antara nilai kriteria pada tabel 3 dengan pembagi. Maka akan di peroleh data seperti pada tabel di bawah ini.

Tabel 4

Matrik Ternormalisasi

\begin{tabular}{lrcrrc}
\hline & Harga & Layanan & Style & Protokol & Lokasi \\
\hline pembagi & 36400,54945 & 5 & 5,385164807 & 4,472135955 & 5 \\
\hline konvensional & 0,274721128 & 0,6 & 0,371390676 & 0,447213595 & 0,6 \\
\hline Barbershop & 0,961523948 & 0,8 & 0,928476691 & 0,894427191 & 0,8 \\
\hline
\end{tabular}

2. Membuat matriks keputusan yang ternormalisasi terbobot (Y). Matrik ini merupakan perkalian antara bobot yang ada pada tabel 2 dengan nilai setiap atribut yang ada pada matrik ternormalisasi atau tabel 4. Matrik ternormalisasi terbobot dihitung dengan menggunakan persamaan berikut

$$
\mathrm{y}_{\mathrm{ij}}=\mathrm{w}_{\mathrm{i}} \mathrm{r}_{\mathrm{ij}}
$$


Hasil dari matrik keputusan ternormalisasi terbobot tampak seperti Tabel 5 berikut

Tabel 5

Matrik Ternormalisasi Terbobot

\begin{tabular}{lccrrc}
\hline & Harga & Layanan & Style & Protokol & Lokasi \\
\hline konvensional & 1,098884512 & 3 & 1,485562705 & 1,788854382 & 2,4 \\
\hline barbershop & 3,846095791 & 4 & 3,713906764 & 3,577708764 & 3,2 \\
\hline
\end{tabular}

3. Menentukan matriks solusi ideal positif $\left(\mathrm{A}^{+}\right)$dan matriks solusi ideal negatif $\left(\mathrm{A}^{-}\right)$dapat menggunakan persamaan

$$
\begin{aligned}
& \mathrm{A}^{+}=\mathrm{y}_{1}^{+}, \mathrm{y}_{2}^{+}, \ldots, \mathrm{y}_{\mathrm{j}}^{+} \\
& \mathrm{A}^{-}=\mathrm{y}_{1}^{-}, \mathrm{y}_{2}^{-}, \ldots, \mathrm{y}_{\mathrm{j}}^{-}
\end{aligned}
$$

dengan

$$
\begin{aligned}
& \mathrm{y}_{\mathrm{j}}^{+}= \\
& \max _{\mathrm{i}} \mathrm{y}_{\mathrm{ij}} ; \text { jika } \mathrm{j} \text { adalah atribut keuntungan } \\
& \min _{\mathbf{i}} \mathrm{y}_{\mathrm{ij}} ; \quad \quad \text { jika } \mathbf{j} \text { adalah atribut biaya } \\
& \min _{\mathrm{i}} \mathrm{y}_{\mathrm{ij}} ; \text { jika } \mathrm{j} \text { adalah atribut keuntungan } \\
& y_{j}^{-}=\max _{i} y_{i j} \text {; } \\
& \text { jika } \mathrm{j} \text { adalah atribut biaya }
\end{aligned}
$$

Pada saat pengisian nilai pada alternatif dan kriteria pada tabel 2, peneliti sudah memberikan keterangan kriteria mana yang termasuk kedalam kelompok biaya / cost maupun kriteria yang termasuk kelompok manfaat / benefit. Sebelum Menentukan matrik ideal positif dan negatif harus ditentukan dulu nilai maksimal dan nilai minimal pada tiap- tiap kriteria. Nilai maksimal dan minimal bisa dilihat pada tabel matrik ternormaliasi terbobot. Apabila kriteria termasuk dalam kelompok benefit (Layanan, Style, Protokol, Lokasi) maka nilai ideal positif adalah nilai yang paling tinggi, sedangkan untuk kriteria yang termasuk 
Ririn Wahyu Arida | Implementasi Metode Topsis...

dalam kelompok cost (Harga) nilai ideal positifnya adalah nilai yang paling rendah

Tabel 6

Matrik Ideal Positif dan Ideal Negatif

\begin{tabular}{cccccc}
\hline & Harga & Layanan & Style & Protokol & Lokasi \\
\hline Max & 1,098884512 & 4 & 3,713906764 & 3,577708764 & 3,2 \\
\hline Min & 3,846095791 & 3 & 1,485562705 & 1,788854382 & 2,4 \\
\hline
\end{tabular}

4. Menentukan jarak antara nilai setiap alternatif dengan matriks solusi ideal positif dan matriks solusi ideal negatif.

a. Jarak antara alternatif dengan solusi ideal positif dapat menggunakan persamaan berikut

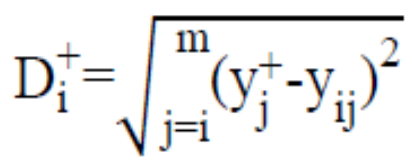

b. Jarak antara alternatif dengan solusi ideal negatif dapat menggunakan persamaan berikut

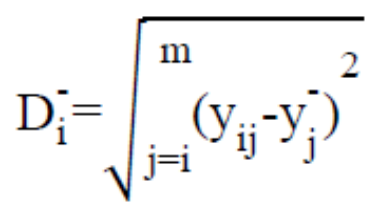

Tabel 7

Jarak Nilai Tiap Alternatif

\begin{tabular}{lcc}
\hline \multicolumn{2}{l}{ D+ } & D- \\
\hline konvensional & 3,667460527 & 2,747211279 \\
\hline barbershop & 2,747211279 & 3,131376254 \\
\hline
\end{tabular}


5. Menentukan nilai preferensi untuk setiap alternatif. Nilai preferensi merupakan kedekatan suatu alternatif terhadap solusi ideal. Nilai preferensi untuk setiap alternatif (Vi) dapat menggunakan persamaan berikut

$$
V_{i}=\frac{D_{i}^{-}}{D_{i}^{-} D_{i}^{+}}
$$

Tabel 8

Nilai Preferensi

\begin{tabular}{ll}
\hline konvensional & 0,428269966 \\
\hline Barbershop & 8,151123764 \\
\hline
\end{tabular}

\section{Kesimpulan}

Dari hasil Nilai Preferensi pada tabel 8 dapat diketahui bahwa Pangkas rambut modern (Barbershop) mempunyai Nilai Preferensi Vi yang lebih besar yaitu sebesar 8,151123764, apabila dibandingkan dengan nilai preferensi pangkas rambut konvensional sebesar 0,428269966. Hal ini menunjukkan bahwa responden lebih memilih menggunak jasa Pangkas rambut modern (B a rbershop) di masa Pandemi Covid 19. Dengan alasan bahwa responden merasa nyaman dengan pelayanan yang diberikan oleh jasa pangkasrambut modern ( barbershop), selain itu jasa pangkas rambut modern ( barbershop) memiliki kelebihan style rambut yang kekinian dan tetap menjalankan protokol kesehatan walaupun harga lebih mahal di bandingkan dengan pangkas rambut konvensional. 
Ririn Wahyu Arida | Implementasi Metode Topsis...

\section{Daftar Pustaka}

HermawanAsep. Penelitian Bisnis Paradigma Kuantitatif. Jakarta: Gramedia Widiyasarana Indonesia, 2005.

Juliyanti, dan Mohamad Isa Irawan dan Mukhlas. "Pemilihan Guru Berprestasi Menggunakan Metoe Ahp Dan Topsis." Prosiding Seminar Nasional Penelitian Pendidikan dn Penerapan MIPA Fakultas MIPA Universitas Negri Yogyakarta, 2011.

Kadarsah, Suryadi. Sistem Pendukung KeputusanSuatu Wacana Struktural Idealisasi Dan Implementasi Konsep Pengambilan Keputusan. Bandung: Remaja Rosdakarya, 2002.

Kusrini. Konsep Dan Aplikasi Sistem Pendukung Keputusan. Yogyakarta: ANDI, 2007.

Littlejhon, steven w\&keren A.fos.2009.teori komunikasi, edisi 9.jakarta : humanika salemba. teori komunikasi, edisi 9. jakarta: humanika salemba, 2009.

Murti, Ahmad Abdul Chamid \& Abdul. "Kombinasi Metode Ahp Dan Topsis Pada Istem Pendukung Keputusan." Prosiding SNATIF ke 4 ISBN 978-602-1180-50-1, 2017

Muzakir, Irvan. "Penerapan Metode Topsis Untuk Sistem Pendukung Keputusan Penentuan Keluarga Miskin Pada Desa Panca Karsa II." ILKOM Jurnal Ilmiah Vol 9 Nomor 3 Desember , 2017.

Raymond McLeod, Jr. Sistem Informasi Edisi 7 Jilid 2. Jakarta: Prenhallindo, 2001.

Turban, Efraim, Jay E Aronson dan Ting Peng Liang. Decision Support Systems and Intelligent Systems. New Jersey: PrenticeHal, 2005.

Wawan firgiawan, Nuralamsah Zulkarnain, Sugiarto Cokro Wibowo. "Komparasi Algoritma Saw, Ahp Dan Topsis Dalam Penentuan Uang Kuliah Tunggal (UKT)." JCIS (Journal Of Computer and Information System) Vol 1 issue 2 ISSN 2622-0881, 2019. 
Ririn Wahyu Arida | Implementasi Metode Topsis...

Windarto, Agus Perdana. "Implementasi Metode Topsis Dan Saw Dalam Memberikan Reward Pada Pelanggan." Kumpulan Jurnal Ilmu Komputer (KLIK) Vol 4 No 1 Februari ISSN 2406 - 7857, 2017.

https://www.liputan6.com/lifestyle/read/4046240/cerita-akhir-pekansejarah-dan-perkembangan-tukang-cukur-di-indonesia. 